\title{
Los Flagston: una auténtica familia americana
}

\author{
ÓSCAR GUAL BORONAT
}

Óscar Gual Boronat (Gandía, 1973) es Doctor en Historia por la Universitat de València y está vinculado profesionalmente al Institut Municipal d'Arxius i Biblioteques de Gandía. Ha colaborado en diversos medios como Volumen, La guía del cómic, Mondosonoro o Tebeosfera. Recientemente ha visto publicado su ensayo Viñetas de posguerra. El cómic como fuente para el estudio de la historia (PUV, 2013).

\section{RESUMEN}

El próximo año se cumplirán seis décadas del debut de Hi and Lois, una de las tiras de prensa de mayor éxito desde el final de la Segunda Guerra Mundial. En ella sus autores, Mort Walker como guionista y Dik Browne como dibujante, reflejaron como ninguna otra serie de aquella época, el asombroso crecimiento económico de la era Eisenhower y los cambios sociales que revolucionarían al país durante la segunda mitad del siglo XX. El objetivo del presente artículo es analizar las claves de su éxito y reivindicar su valor historietístico.

\begin{abstract}
Next year marks six decades of the debut of Hi and Lois, one of the successful comic strips since the end of World War II. The writer Mort Walker and the artist Dik Browne reflected as any other comic strip, the amazing economic growth of the Eisenhower's era and the social changes that would revolutionize the country during the second half of the twentieth century. The aim of this paper is to analyze the keys to its success.
\end{abstract}




\section{Introducción}

En una viñeta perteneciente a la tira del 16 de abril de 1954 de Beetle Bailey, el protagonista, relevado ya de su paso por el ejército, huye disimuladamente ante el escenario que está tomando forma en el salón de la casa de sus padres. Allí todos los presentes discuten acerca de cómo Beetle ha de orientar su vida a partir de ese momento. Su padre le recomienda que vaya buscando un trabajo, su madre no está de acuerdo y cree que debería volver a la universidad, su hermana Lois, en cambio, considera que lo más acertado sería casarse y sentar la cabeza, su cuñado afirma que montar un negocio propio es la mejor opción, e incluso su sobrino mayor opina, y le sugiere volver a alistarse. Y será este último consejo el que seguirá a pies juntillas, dando por concluido así su breve regreso a la vida civil. La razón de ese prematuro, efímero y sorprendente licenciamiento se debió al enfado del autor de la serie, Mort Walker, ante la decisión de la revista militar Star \& Stripes, en su edición japonesa, de dejar de publicarla, al considerar que su contenido cuestionaba la autoridad de los mandos. La noticia tuvo una gran repercusión en los medios, que junto con los numerosos seguidores presionaron para lograr la reincorporación del personaje a la disciplina cuartelaria en Camp Swampy, logrando además que la difusión de Beetle Bailey se ampliara con licencias para otro centenar de periódicos.

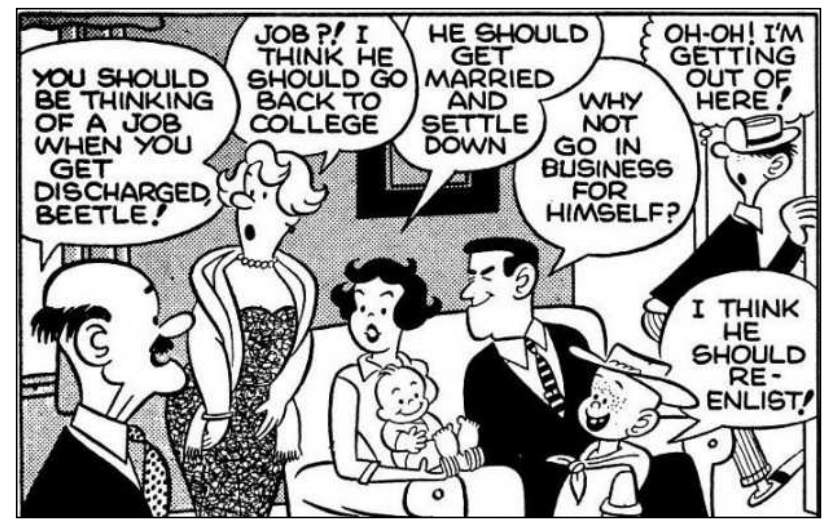

FIG. 1. Viñeta perteneciente a la tira de Beetle Bailey del 16 de abril de 1954.

Originariamente dicha strip (tira de cómics que aparecía diariamente en los periódicos), la última aprobada en persona por William Randolph Hearst como 
propietario de King Features Syndicate, arrancó el 4 de septiembre de 1950 como una comedia de alumnos universitarios encabezados por un estudiante holgazán y aprovechado. Sin embargo su irregular trayectoria (el syndicate, la agencia encargada de distribuir este tipo de contenidos a la prensa, estuvo a punto de no renovar el contrato) conoció un punto de inflexión cuando Beetle, en cierta manera obligado por su bravuconería, acudió a la oficina de reclutamiento a alistarse el 13 de marzo del año siguiente, una decisión clave en la evolución de la misma. De esa manera la serie creció gracias al rico elenco de nuevos personajes secundarios, sumado a la habilidad de Walker, quien fuera oficial de inteligencia en Italia durante la Segunda Guerra Mundial, para criticar las contradicciones de la vida castrense y para reflejar la actualidad social más inmediata. En ese momento las hostilidades en Corea estaban entrando en un largo y tenso paréntesis. Solo dos meses antes los batallones chinos, con apoyo militar soviético, habían tomado la capital surcoreana, Seúl, por segunda vez desde que estallara el conflicto en el verano anterior. Poco a poco las tropas de los EE. UU. y de sus aliados siguieron recuperando terreno hacia el norte, y a mediados de año alcanzarían nuevamente el paralelo $38^{\circ}$. Aunque jamás fuera enviado al frente y permaneciera eternamente en su base, la decisión de destinar a Beetle a la infantería en plena guerra fría supuso un renacimiento para el personaje (con el paso de los años crecería de 200 a 1.100 rotativos de todo el mundo) ${ }^{1}$ y el inicio de la consolidación de su creador.
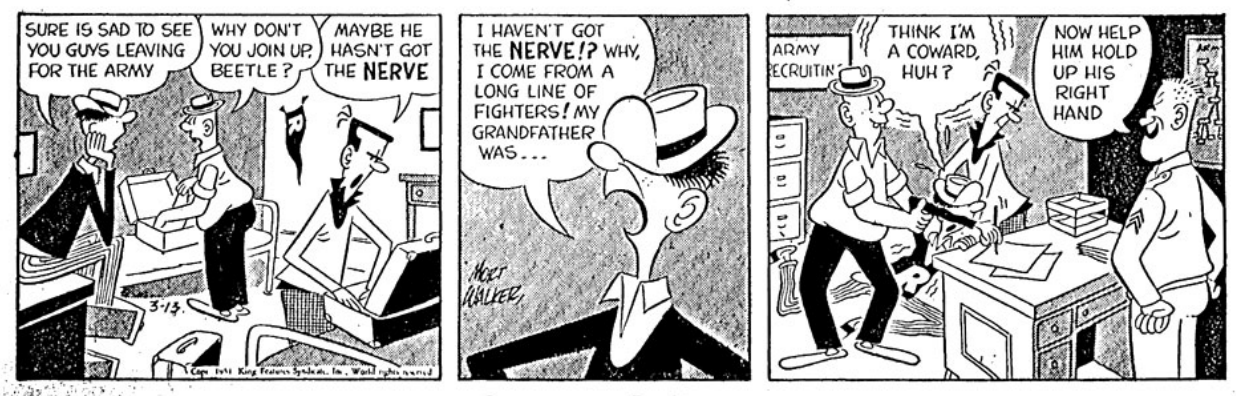

FIG. 2. Tira diaria de Beetle Bailey perteneciente al 13 de marzo de 1951.

\section{${ }^{1}$ http://beetlebailey.com/about/}

CuCo, Cuadernos de cómic número 1. Septiembre de 2013 


\section{Una nueva familia}

En 1953 Walker sería reconocido con el principal galardón de la industria, el premio Reuben concedido por la National Cartoonist Association, que le serviría como empujón en su prolífica y fructífera carrera como historietista. A partir de esa fecha y a lo largo de las siguientes tres décadas llegaría a poner los cimientos, sin contar su serie estrella, junto con toda una serie de colaboradores, de un total de siete tiras diarias diferentes (Hi and Lois, Mrs. Fitz's Flats, Sam's Strip, Boner's Ark, Sam and Silo, The Evermores y Betty Boop and Felix), algo no habitual en autores cuyas series superan el millar de periódicos, que prefieren concentrarse en sus personajes de éxito. El primer paso lo daría recuperando precisamente aquel anecdótico episodio familiar que describíamos al principio. La visita, en apariencia intrascendente, de Lois y de su marido Hiram a la residencia familiar, acompañados de sus tres hijos, para saludar al tío Beetle, sin demasiado éxito, pues este llevaba durmiendo desde el día anterior, tendría consecuencias unos meses después. En concreto a partir del 18 de octubre del mismo año, cuando dichos personajes, al parecer muy bien recibidos por los lectores habituales, adquirirían su propia serie: Hi and Lois, en uno de los primeros spin-off de la historia de los cómics. Pero de primavera a otoño la familia Flagston, que así se llamaban, sufriría importantes transformaciones a más de un nivel. Hiram, ahora conocido por su diminutivo, Hi, perdió su rostro duro y serio por uno más cordial, su corte de pelo era algo menos anticuado, su nariz se acható y sus ojos se agrandaron; Lois siguió conservando su figura y sus rasgos, aunque el color de la melena pasó de negro a rubio; el mayor de los niños, que ya en sus primeras apariciones perdía sus gafas o poblaba de pecas su cara de un día para otro, creció considerablemente y se acercó a la adolescencia; la niña juntó sus dos coletas en una al tiempo que, como su madre, aclaraba el tono de su cabello, y el bebé también ganó en consciencia y personalidad. No obstante el cambio tal vez más significativo fue en cuanto al número de miembros, el tamaño de la prole, que pasaron a ser cuatro, y a tener nombres propios: Chip, peligrosamente parecido a su tío Beetle en actitud y apariencia, los gemelos Ditto y Dot, y la pequeña Trixie, sin mencionar a Dawg, el enorme perro lanudo. Todos listos para

CuCo, Cuadernos de cómic número 1. Septiembre de 2013 
convertirse en una de las series de más éxito dentro de la nueva corriente de los cómics para la prensa que empezaba a despuntar.

Las series de humor de los periódicos lograron su popularidad, a inicios del siglo $\mathrm{XX}$, a partir del principio de continuidad, los mismos personajes entrega a entrega, los mismos escenarios, las mismas situaciones. Resultando agradablemente reconocibles, y en cierta manera, previsibles para el público. El paso del formato de página de viñeta única que se publicaba los domingos al de tira de varios paneles de aparición diaria supuso la consolidación de un público más adulto así como de un nuevo género, la llamada family strip. ${ }^{2}$ Desde Polly and Her Pals (1912) hasta Blondie (1930) los primeros decenios de la centuria conocerán la consolidación del mismo con títulos como Bringing Up Father (1913), The Gumps (1917), Gasoline Alley (1918) o Little Orphan Annie (1924), una proliferación que no se repetiría hasta veinticinco años después aunque no en la misma línea. Curiosamente el nivel de sátira era mucho más elevado en el trabajo de aquellos pioneros que en el de sus herederos de generaciones artísticas posteriores. Los clanes que dieron nombre a aquellas antiguas series resultaban mucho menos convencionales y más heterogéneos que las familias que vendrían más adelante, socialmente más conservadoras. Tanto la obra de Cliff Sterrett como la de Chic Young, las que abrieron y cerraron esa época dorada respectivamente, arrancaron como seriales interpretados por bellas jovencitas con una vida social ajetreada, que bien por el peso de otros actores o por la propia evolución del guion evolucionaron hacia un protagonismo colectivo. Blondie Boopadoop sentó la cabeza eligiendo, de entre sus numerosos pretendientes, a Dagwood Bumstead, quien fue desheredado por contraer matrimonio con quien no debía. Jiggs, el héroe del cómic de George McManus, es un borrachín, jugador empedernido, que quiere perder de vista a su esposa, Maggie, obsesionada en aparentar lo que no es. Un tono muy similar al que Sidney Smith imprimió en las desventuras de Andy Gump, totalmente sometido a la dominante Minerva. Contextos alejados de lo que definiríamos como habitual, algo que llega a su

\footnotetext{
${ }^{2}$ García, S. La novela gráfica. Bilbao, Astiberri, 2010, p. 75.
} 
máxima expresión con Walt Wallet, en Gasoline Alley, y Oliver Warbucks, en Little Orphan Annie, padres adoptivos, cabezas de familias que podríamos denominar uniparentales. El uno por criar al pequeño Skeezix en solitario durante tantos años, el otro por tener como esposa a una odiosa mujer, que en cuanto puede devuelve a Annie al orfanato. Ficciones que progresan basándose en el encadenamiento, la persistencia, la prolongación.

En la segunda posguerra la tendencia será bien diferente. Como bien explica Antoni Guiral en el segundo tomo de su imprescindible Del tebeo al manga: Una historia de los cómics, con la irrupción de la televisión los syndicates empiezan a apostar con decisión por las tiras de humor. ${ }^{3} \mathrm{Si}$ tenemos en cuenta que en 1952 la Federal Communication Commission retomó la concesión de licencias de emisión, que había estado bloqueada durante cuatro años, "una vez las estructuras institucionales y los modelos de programación ya estaban firmemente elaborados", ${ }^{4}$ y que pocos años más tarde aproximadamente un tercio de los hogares estadounidenses poseían receptor de televisión, era indudable que el nuevo medio marcaría tendencias y modelos de entretenimiento. Tras el éxito que cosecharon los espectáculos de variedades a finales de la década anterior, y el buen recibimiento de los llamados dramas de repertorio, con el arranque de los cincuenta comenzó a imponerse la comedia de situación, sobre todo a partir de que I love Lucy, de la cadena CBS, se convirtiera en el programa número uno en los índices de audiencia. El formato venía a ser una hábil mezcla entre los sketches humorísticos que se intercalaban en los magacines y los seriales de tradición radiofónica, sustituyendo "el melodrama —lejos de la tradición cultural norteamericana- por las historias cotidianas de gente corriente y la pasión desenfrenada por la sonrisa amable e incluso la carcajada". ${ }^{5}$ Algunas de sus

\footnotetext{
${ }^{3}$ GuIRAL, A. (coord.). Del tebeo al manga: Una historia de los cómics. Vol. 2, Torroella de Montgrí, Panini, 2007, p. 19.

${ }^{4}$ WYVER, J. La imagen en movimiento: Aproximación a una historia de los medios audiovisuales. Valencia, Filmoteca de la Generalitat Valenciana, 1992, p. 154.

${ }^{5}$ Barroso García, J. Realización de los géneros televisivos. Madrid, Síntesis, 2002, p. 282.
} 
características serían incluso adoptadas por los cómics de prensa (abordar con actualidad cualquier preocupación social, reflejo de la vida ordinaria y de los personajes comunes, dramas ligeros de cocinas y cuartos de estar, protagonismo de los diálogos y de los gestos), en su intento de imponer un gag al día, dejando de lado aquel clásico afán de continuación, de consecuencia, descrito con anterioridad, que habían cultivado las daily strips familiares desde sus orígenes.

Pero, pese a su evidente importancia, no fue solo la influencia de la televisión la que indujo a los syndicates a potenciar a mediados de la década este tipo de series. Richard Marschall apunta otra razón más: la necesidad de la prensa, tras las consecuencias de la investigación senatorial acerca del influjo de los tebeos de terror sobre los jóvenes lectores, de dar cabida en sus páginas a otro tipo de cómics totalmente alejados de aquellos que Frederic Wertham había analizado y denunciado en su estudio. La imposición del Comics Code (como mecanismo de autocensura dentro de la industria) y la negativa imagen de los comic-books obligaron a suavizar los argumentos de las tiras de prensa. Durante la guerra mundial el tipo de historietas que más se popularizó fue el de aventuras y pocos personajes humorísticos sobrevivieron al conflicto sin verse involucrados en él, sin haber sido movilizados de una u otra forma. Además la enorme notoriedad de las series de humor que habían debutado pocos años antes, como Pogo (1949) de Walt Kelly, Peanuts (1950) de Charles Schulz, Dennis, the menace (1951) de Hank Ketcham, o la propia Beetle Bailey, entre otras, demostró que la comedia tenía su sitio, nuevamente, en los periódicos. En ese contexto propicio, Walker, que como la gran mayoría de autores nombrados era un cartoonist, es decir, provenía en origen de las secciones de humor gráfico de las revistas, recibió una oferta de su amigo Lew Schwartz para escribir una family strip sindicada que estaba preparando, y de la cual no se sentía demasiado satisfecho. Schwartz era por esa época un dibujante sin excesiva fortuna, que pese a haberse iniciado en el negocio muy joven (con apenas diecinueve años colaboraba con Rodlow Willard en Scorchy Smith), no había conseguido todavía ver impresa su firma en las planchas que realizaba. Sus más de siete años y sus 240 páginas anuales como negro de Bob Kane en los tebeos de Batman únicamente le habían reportado, a nivel profesional, el ser acreditado, junto con el 
omnipresente Kane y el guionista David Vern Reed, como creador del personaje Deadshot. Y una vez más vio como la suerte le daba la espalda cuando King Features recordó al creador de Beetle Bailey que su contrato le prohibía colaborar con otra agencia. Pese a ello no descartaron del todo el proyecto y propusieron a Walker que les presentara algunas ideas al respecto. Estas fueron muy bien recibidas, principalmente porque el ocio de las familias se estaba convirtiendo en un negocio dentro del mercado de consumo (más de 11 millones de matrimonios se contrajeron en EE. UU. entre 1950 y 1954, el 67,4\% de la población adulta del país estaba casada), lo cual aconsejaba recuperar la comedia familiar. Pronto él mismo y Sylvan Byck, el editor, buscaron al dibujante adecuado.

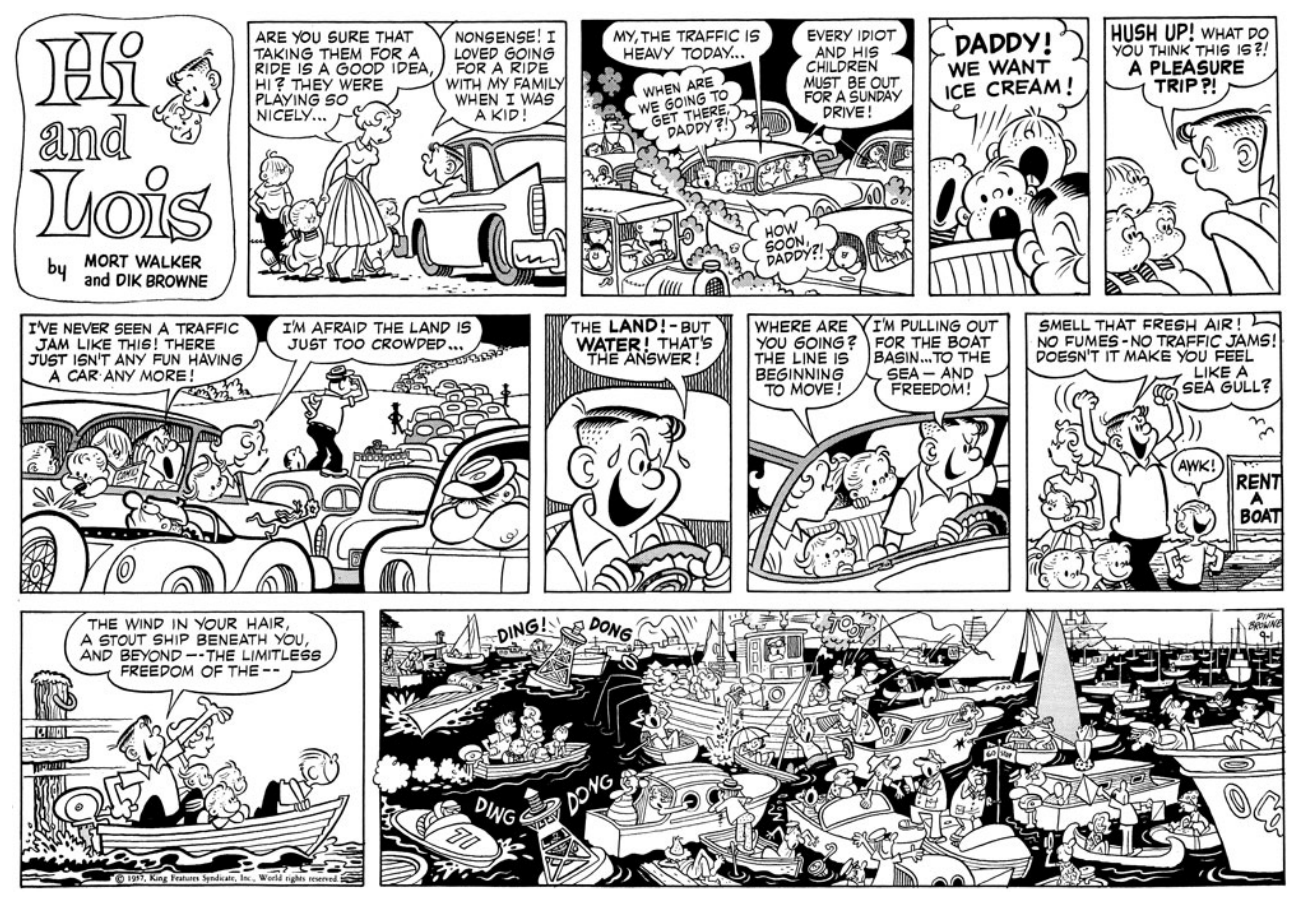

FIG. 3. Página dominical de Hi and Lois del 1 de septiembre de 1957.

\section{Buscando su lugar}

Dik Browne, quien había trabajado como ilustrador para cabeceras de prestigio como New York Journal o Newsweek, pertenecía a la plantilla de la agencia publicitaria 
Johnstone and Cushing donde se ganaba muy bien la vida. Así que cuando habló con Byck no acabó de convencerse, tenía serias dudas acerca de cambiar de oficio y conocía a dibujantes que no habían podido aguantar la presión de crear una tira cada día. Pese a ello cuando conoció a Walker congeniaron inmediatamente ("Nos tomamos unas copas y discutimos sobre catolicismo", recordaba) y se dieron cuenta de que juntos podían hacer un buen trabajo. Se pusieron manos a la obra rediseñando los primitivos bocetos de Walker, cada uno a su manera, para hallar puntos en común, intentando establecer cual iba a ser el estilo de la serie. Los diseños de Browne eran en principio demasiado serios, con líneas rectas y ángulos muy pronunciados, alejados de lo que estaban buscando, por lo que tuvo que dulcificarlos con más curvas. "Si tienes a dos tipos que no poseen exactamente el mismo estilo de dibujo, es difícil fusionarlos" afirmaba Walker, a lo que Browne añadía: "Mort dibujó los personajes originales. Eso estableció todo lo que vino a continuación. Cuando dibujas un personaje como $\mathrm{Hi}$, por ejemplo, inmediatamente estás marcando cual va a ser el estilo de toda la tira. Ya estás dictando cómo va a ser un árbol o cómo va a ser un perro, únicamente con abocetar una cabeza. Fue complicado aceptar este hecho cuando empecé a realizar Hi and Lois, pero lo logré. Afortunadamente funcionó muy bien". ${ }^{6}$ El resultado ha sido bautizado con el tiempo como heredero o renovador del "the big foot style" (una tradición estilística que se remontaría a Frederic B. Opper o Elzie C. Segar, pasaría por Billy D. Beck y llegaría hasta Robert Crumb, y que algunos ilustradores utilizaban de manera despectiva para referirse al trabajo de los caricaturistas), o más concretamente como "the Connecticut style", por la casualidad de que, a parte de Walker y Browne, otros residentes del condado de Fairfield, en Connecticut, eran dibujantes de prensa (Stan Drake, Jerry Dumas, Dick Hodgins, Mel Casson, o Gilbert “Gill” Fox). Por supuesto aquello solo era el principio y la imagen de los protagonistas se fue conformando poco a poco.

\footnotetext{
${ }^{6}$ Todas las declaraciones de Mort Walker y Dik Browne están extraídas de WALKER, B. (ed.). The Best of Hi and Lois. New York, Comicana, 1986.
}

CuCo, Cuadernos de cómic número 1. Septiembre de 2013 

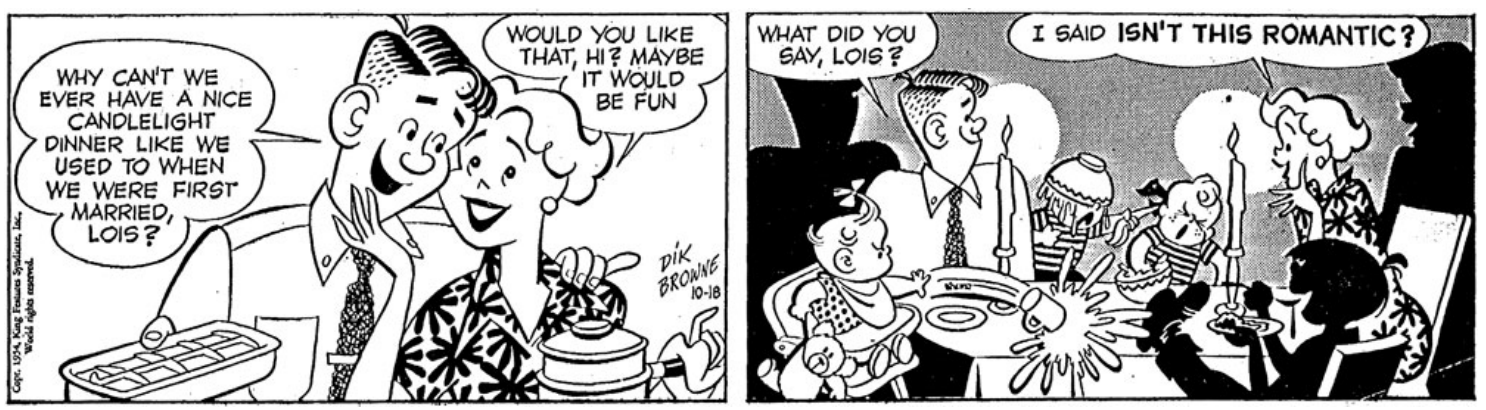

FIG. 4. Primera daily de Hi and Lois perteneciente al 18 de octubre de 1954.

Más sencillo fue marcar cuales serían las líneas maestras del guion, basadas en dos intenciones: reflejar el modo de vida de los hogares norteamericanos del momento y mostrar la cara amable de la familia. Querían padres que se amaran el uno al otro e hijos que los respetaran, el amor como fuerza de vida, sin rastro de mezquindad, ni dobles significados, ni mala leche, solo simpatía y optimismo. La primera daily es bastante explícita en este sentido, arranca con una viñeta en la que Hi y Lois juntan sus caras en una romántica pose mientras él sugiere preparar una cena a la luz de las velas. A renglón seguido los lectores descubrimos que no están solos, que tienen cuatro retoños. Y pese a ello, por encima del griterío y el jaleo que los niños están armando, se muestran encantados con la idea. Durante la semana siguiente, y en el primer arco argumental, que traiciona en cierta manera el espíritu del gag-a-day, el matrimonio Flagston, reconociendo que su viejo apartamento ya no da más de sí, se dedicará a buscar una nueva casa, decidiéndose por una bonita vivienda unifamiliar a las afueras de la ciudad. Un cambio lógico que estaba desarrollándose por todo el país, cuando las familias blancas de clase media en un auténtico y paulatino movimiento demográfico estaban abandonando el centro de las ciudades para instalarse en las crecientes zonas suburbiales.

Dentro de las mismas áreas metropolitanas se dio una redistribución aún más dilatada, cuando la gente abandonó las ciudades y se fue a vivir a las afueras. El traslado a estas, latente desde los años veinte, se convirtió en un éxodo masivo tras la Segunda Guerra Mundial. Se dieron distintas influencias: la construcción de grandes urbanizaciones nuevas [...], los créditos federales para la adquisición de la vivienda, nuevas carreteras y vías rápidas, la posesión casi universal de coches. Entre 1950 y 1980 la mayoría de las ciudades estadounidenses perdieron población a favor de los alrededores. [...] En 1960 ya vivía más gente en las

CuCo, Cuadernos de cómic número 1. Septiembre de 2013 
afueras que en el centro de las ciudades. [...] De ese modo dejaron de ser solo dormitorios y se hicieron social y económicamente autosuficientes. ${ }^{7}$

Con una tasa de natalidad que se situaba en 37,2 nacimientos por cada mil habitantes en la primera mitad de la década de 1950, y únicamente en dos puntos menos el lustro siguiente, las familias numerosas (con tres o cuatro hijos) eran muy habituales. Familias que esperaban hallar vivienda a precio accesible en las áreas conurbanas, en las nuevas comunidades que estaban surgiendo, donde todas las residencias tenían el mismo aspecto. Urbanistas como William J. Levitt levantaron esas construcciones con las técnicas de la producción en masa, con casas prefabricadas cuyo montaje se realizaba, en parte, en la fábrica y no en su ubicación definitiva. Eran moradas modestas pero que rebajaron los costes, multiplicándose en poco tiempo, y permitieron que nuevos propietarios alcanzaran una ansiada parte del sueño americano (en la daily del 14 de diciembre de 1960 uno de los convecinos más ancianos de la urbanización donde residen los Flagston reconoce con añoranza cuando todas aquellas tierras eran zonas de cultivo, con granjas y ganado, ante este relato Dot pregunta asombrada cuanto tiempo hace de eso, a lo que el viejo, con cara de circunstancias, responde: "Dos años"). Al crecer los suburbios, las empresas también se mudaron a las nuevas áreas; proliferaron grandes centros comerciales (de ocho en todo el territorio estadounidense al final de la Segunda Guerra Mundial se pasó a 3.840 en 1960), donde se reunían una gran variedad de tiendas, cambiando los hábitos de consumo (Hi y sus hijos permanecen más tiempo en el coche, buscando una plaza para aparcar, que en la tienda en la plancha del 13 de noviembre de 1954). Con cómodos estacionamientos y horarios vespertinos accesibles, esas instalaciones permitían que sus clientes nunca tuvieran que ir de compras al centro de la ciudad. A todo ello contribuyó en gran medida la Ley de Carreteras de 1956 que invirtió 26.000 millones de dólares, la asignación más elevada destinada a obras públicas en la historia de los EE. UU., en la construcción de 64.000 kilómetros de carreteras interestatales.

\footnotetext{
${ }^{7}$ Jones, M. A. Historia de EE. UU.: 1607-1992. Madrid, Cátedra, 1996, p. 527.
} 


\section{Cada uno en su papel}

No cabe duda que Walker y Browne habían logrado, en solo ocho entregas, dar entrada en $\mathrm{Hi}$ and Lois a la realidad más inmediata a través de uno de los temas que más preocupaban a sus lectores, al tiempo que trazaban algunos de los principales rasgos que definirían a cada uno de los progenitores. Hiram más realista, con los pies en el suelo, Lois más entusiasta. Mientras él temblaba cavilando sobre las consecuencias de haberse embarcado en aquella aventura inmobiliaria, ella pensaba en contárselo a su madre y en empezar a decorar su hogar. Cuando se inició la serie él rondaría perfectamente la treintena, como Mort Walker (Browne era seis años mayor), al menos eso se deduce de sus propias palabras, o de la edad de su anciano padre, el cual ante la curiosidad de su nieto Ditto reconoce —en la tira correspondiente al 30 de octubre de 1974- haber conocido a lo largo de su vida cosas buenas (los automóviles, los aviones, los cohetes, la penicilina, la radio, la televisión o los abrelatas) y otras no tanto (cuatro guerras, contaminación, inflación, películas X, el aumento en los índices de criminalidad y al periodista deportivo Howard Cosell). Hi tiene una hermana pequeña, creció durante la Gran Depresión (daily del 2 de febrero de 1960, sunday del 29 de julio de 1962), y aunque no lo confiese nunca, podríamos especular con la posibilidad de que fuera veterano de guerra (a los que, por otro lado, se les concedieron prestamos para la adquisición de viviendas). Trabaja en Foofram Industries como ejecutivo de ventas, un trabajo de cuello blanco como el de la mayoría de estadounidenses en 1956, cumple con sus obligaciones como ciudadano, y sus principales distracciones cuando tiene tiempo libre son la jardinería, pese a reconocer que es un trabajo duro (dominical del 3 de julio de 1966), y jugar al golf. Se confiesa enamorado de su esposa (en más de una ocasión ambos se preguntarán porqué conforman uno de los pocos matrimonios de su entorno que continúan juntos, rodeados, como estarán, de divorciados), orgulloso de sus hijos, contento con su vida, pese a que el psicólogo de la empresa no se lo acabe de creer (25 de enero de 1956). Con la edad conseguirá dejar de fumar —un hábito del que, para ser sinceros, no llegó a abusar nunca, alguna pipa de vez en cuando- y ganará algo de peso.

CuCo, Cuadernos de cómic número 1. Septiembre de 2013 
Lois, guapa y elegante, estricta y decidida, tierna y valiente, es la mayor de la familia Bailey (Beetle es el mediano y Bruiser el pequeño), con los treinta años cumplidos. Será desde el principio una activista vecinal y un ama de casa orgullosa de su tarea, sin por ello renunciar a los placeres que la vida tiene reservados para los matrimonios jóvenes. Son, de hecho, una pareja muy afable, no únicamente con los vecinos y familiares, constantemente son invitados a fiestas, a cenas y celebraciones particulares que, al parecer, se celebraban con frecuencia. Existen ejemplos brillantes de esta costumbre social a lo largo de toda la trayectoria de Hi and Lois, como la sunday del 24 de noviembre de 1963, cuando creyendo que van a asistir a una íntima reunión en la residencia de los Farley se verán literalmente desplazados, hasta el punto que el bueno de Hi solo encontrará sitio en el jardín. O cuando, en la entrega del 23 de diciembre de 1960, al volver tarde del trabajo en el centro de la ciudad, él comenta con su colega Fred lo agotado que está, y que espera que Lois no haya aceptado ninguna estúpida invitación para ese día. Su amigo, antes de despedirse, opina lo mismo, confesándole que odia profundamente esas aburridas fiestas con gente que apenas conoces, con la que no sabes de qué hablar. Pero son ellas las que deciden, y en la última viñeta vemos al matrimonio Flagston en la puerta de la casa de Fred esa misma noche. También les gusta bailar, aunque sea disimuladamente en el salón de su casa, salir con los amigos, y acudir a todo tipo de eventos. Tal vez lo único que eche en falta Lois de vez en cuando sea ir al cine, por desgracia ninguno de los títulos en cartel es del gusto de su esposo, aunque siempre acaba por reconocer que ya no se hacen películas para ellos.

Como decíamos su dedicación principal es el hogar (la cocina, la limpieza, el orden y el aseo), como no podía ser de otra manera en una mujer de su época, casada y con muchos hijos. Su marido le echará una mano de vez en cuando, muy de vez en cuando, le cuesta levantarse de su cómoda hamaca, o dejar el periódico a medio leer sin rechistar, incluso en lo referente a aquellas tareas manuales que se suponen destinadas a los hombres. Durante largos periodos habrá una sombra que le persiga para recordarle los trabajos pendientes, un tarro de cristal en el que Lois le irá colocando notitas de papel con las faenas continuamente aplazadas, conocido en la casa como the job jar. 
Curiosamente le costará menos asumir el rol de ella — delantal incluido, como no podía ser menos en una tira estrictamente cómica-, cuando está ausente o cuando, ya en la década de 1980 y en un socialmente irreprochable giro argumental, Lois se incorpore al mercado laboral. Será como agente inmobiliario y supondrá una importante fuente de chistes para Walker, tanto en las repercusiones dentro de casa, como en la reacción del entorno. Si hasta entonces la aparición de mujeres trabajadoras (las bellas secretarias en la oficina de Hiram, las dependientas de las tiendas, las maestras de los niños), o la decisión de asignarle a él el papel de ama de casa temporal, eran anécdotas en el primer caso o bromas de un día en el segundo, todo cambia con la entrada de la protagonista en esa nueva esfera. Se adelanta así en años a otra histórica ama de casa de los cómics en convertirse en mujer trabajadora, Blondie Bumstead no montará su negocio de comida casera y catering hasta entrados ya los noventa.

Ese deseo por parte de los responsables de la serie de hacer progresar el mundo de sus creaciones al compás, más o menos, de la realidad que les rodea es asimismo reseñable en aquello concerniente a los niños Flagston. En el paisaje de la tira se aprecian los cambios sociales, las preocupaciones ciudadanas, la actualidad, con una cadencia propia, pero sin que ello conlleve apreciables transformaciones físicas en los personajes. Hi y Lois se les verá algo más maduros, aunque envejecen al ritmo de la ficción, y lo mismo ocurre con sus hijos. De entre ellos Chip puede que sea con toda probabilidad el que conozca un mayor desarrollo, lo cual no se ha de entender como una traición a sus hábitos. Aquel que jamás se ha mostrado como un hermano mayor responsable, seguirá sin asumir sus responsabilidades cuando crezca, nunca recogerá ni pondrá orden en su cuarto, y solamente aceptará, por poner una muestra, un empleo como repartidor de periódicos pensando que ganaría mucho más dinero. Se mantiene eternamente adolescente, cada vez más interesado en las chicas (lo cual le hará estar siempre preocupado por su estatura) y menos en sus estudios. Sabe reconocer el esfuerzo que han hecho sus padres con él, pese a que jamás lo reconocerá ante ellos, escuchará con atención los consejos de su padre sin hacerle nunca demasiado caso y será demasiado consciente de las diferencias generacionales que les separan. Se adaptará con facilidad a las nuevas corrientes de pensamiento de los sesenta (el 
pacifismo, el antimaterialismo, el antimilitarismo), sin entender muy bien lo que significan (al mismo tiempo que tacha a sus padres de avaros y burgueses aceptará de buen grado todas las comodidades materiales de la clase media), haciendo responsables a sus progenitores de los males del mundo, algo en lo que, por cierto, también estará de acuerdo el propio Hi. Acomodará su corte de pelo, su ropa (gorra, vaqueros rasgados, camisetas con mensaje) y sus aficiones (los bongos, mascar chicle, tocar la guitarra, escuchar música en su flamante aparato de alta fidelidad) a las modas, se colgará del teléfono eternamente, insistirá en ver películas subidas de tono, nada fuera de lo común. Será sin duda el vástago que más peso tendrá de toda la familia, posiblemente por ser el mejor vehículo para manifestar las mutaciones de la sociedad norteamericana durante cuatro décadas.
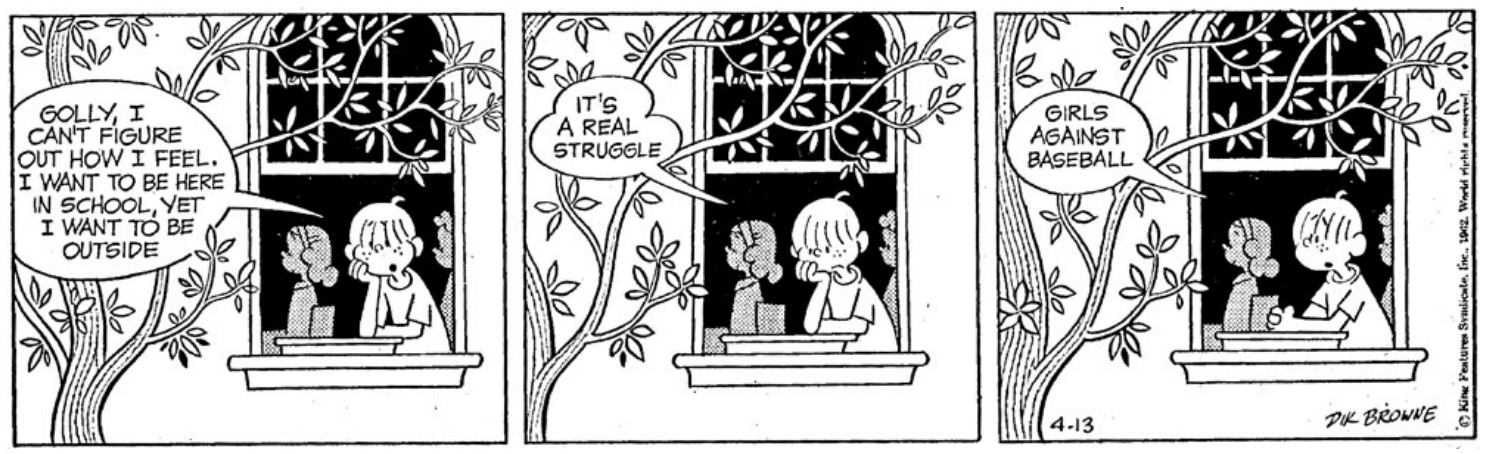

FIG. 6. Daily del 13 de abril de 1962 de la serie Hi and Lois.

En orden de importancia el segundo puesto le correspondería sin duda a la más pequeña, a Trixie, el bebé que jamás andará, ni pronunciará ninguna palabra inteligible, (excepto en los momentos en que no hay nadie alrededor que la pueda oír), que no sea para llamar a su madre. Trixie es consciente en todo momento de lo que ocurre a su alrededor, sin acabar de comprenderlo muy bien. Los lectores conoceremos sus razonamientos y reacciones a través del clásico globo de pensamiento (una herramienta que introduciría y popularizaría en los cómics para la prensa Snoopy, y heredarían otros como Garfield o Marvin), así como sus largas conversaciones, en las que no obtiene réplica alguna, con Dawg, la mascota, con los árboles del jardín, o con un amigo inesperado que aparecerá en diversas ocasiones, el rayo de sol que entra por la ventana. 
Si bien le gustaría recibir más atención por parte de los que le rodean, siempre ocupados, siempre jugando, siempre peleando, posee una gran imaginación, y un rico mundo interior que la dotará de personalidad. Tal vez lo que les falta a sus hermanos, los gemelos Dot y Ditto. Posiblemente por esa condición de mellizos tienen una dependencia mutua, muy poco peso específico el uno sin la otra y viceversa. Sus apariciones suelen ser en pareja, sobre todo en una primera etapa, cada uno con sus obsesiones, Ditto por las galletas, la televisión y los juguetes de vaqueros, o de astronautas, según manden las tendencias, Dot por crecer, por los juegos de adultos, por los secretos de las mujeres. Es cierto que con el paso de los años, con la entrada en el colegio, se distancian un poco, pero seguirán representando un rol poco innovador, aunque puede que clave dentro del género de comedia familiar, el de los niños sinceros, un tanto ingenuos, que no entienden demasiado bien el mundo de los adultos, y cuyas reacciones son las que propician, en la última viñeta, el chiste final. Ditto es algo más cándido, e inoportuno, suele cuestionarlo todo, varias veces, como si se le escapara algo. Le gusta acompañar a su padre a los partidos de futbol americano, y acribillarlo a preguntas a lo largo del camino de vuelta a casa. Dot, puede que por su condición femenina, resulta más despierta, un tanto más madura, más consciente.
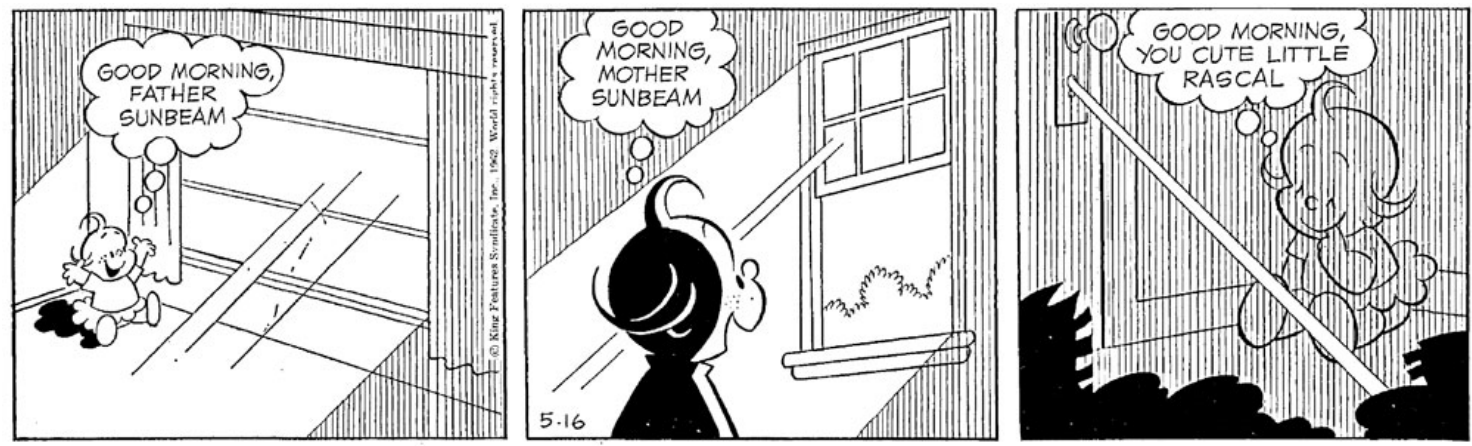

FIG. 7. Tira de Hi and Lois del 16 de mayo de 1962.

Como conjunto no cabe duda que eran una familia totalmente convencional, con sus cuitas, sus problemas, sus preocupaciones y sus diferencias. Disfrutan de sus momentos juntos, aprovechan las vacaciones para conocer el país y los domingos para asistir a la iglesia. De sinceras convicciones religiosas (son varias las tiras en las que los 
vemos endomingados atendiendo al sermón o rezando en el banco, en episodios como los del 6 de noviembre de 1978 o el del 28 de junio de 1985, destacando por encima de cualquiera de ellos la deliciosa entrega del domingo 17 de abril de 1960, todo un canto al optimismo, en el que Browne realiza un portentoso alarde de detallismo, de escenificación, mostrando su talento), no llegan a hacer pública cual es su confesión, bien sea protestante (68 millones de fieles en EE. UU. en 1960) o católica (49 millones). Celebran todas las festividades, asisten a acontecimientos deportivos y a celebraciones cívicas, no les gusta ir a la escuela, ni al trabajo. En resumidas cuentas, son felices.
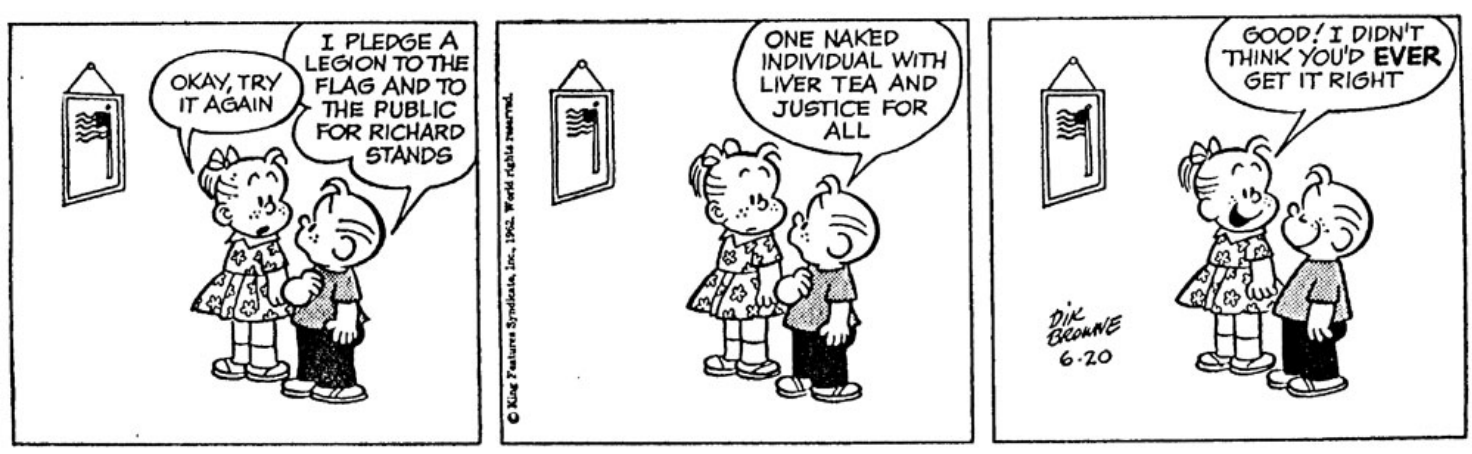

FIG. 8. Entrega de Hi and Lois correspondiente al 20 de junio de 1962.

A su alrededor harán acto de aparición otros actores secundarios, cuya impronta en el devenir del serial será totalmente coyuntural. Entre la segunda mitad de los cincuenta y la primera de los sesenta fue habitual la presencia de los basureros del barrio, Abercrombie, con algo de sobrepeso y la colilla siempre en la boca, y Fitch, más entrados en años, enjuto, sempiterno fumador de pipa, que tomaban sus nombres de unos prestigiosos sastres neoyorquinos, o la del jefe de Hi, el Sr. Foofram, el gerente y propietario de Foofram Industries, empresa heredada de su padre, que jamás conoceremos muy bien a qué sector productivo se dedica. Hubo otros con sus correspondientes tics reconocibles, pequeños defectos cómicamente aprovechables, pero sin demasiado juego: el lavandero chino Foo Yung, el único personaje de otra raza que asomaría más de una vez, absorbido por la corrección política respecto a las minorías étnicas y por las lavanderías automáticas; el torpe cuñado Bruiser, con mucho menos jugo que sus hermanos mayores; el joven matrimonio Newlyweds, o el Dr. Gargle. De 
entre todos ellos el único que logró asentarse fue Thirsty Thurston, vecino de los Flagston, gordo, vago, bebedor y mediocre jugador de golf. Su flequillo rebelde, su nariz morada, los ojillos semicerrados, le dotaban de una envidiable comicidad física. Definido como una mezcla entre Andy Capp y Olaf (Hägar era su nombre original), estaba considerado como una mala influencia por Lois, quien continuamente le reprochaba la actitud para con su esposa Irma, trabajadora incansable, lógicamente desencantada (como muestras las entregas del 27 de abril de 1963 o la del 10 de octubre de 1965 son bastante elocuentes).
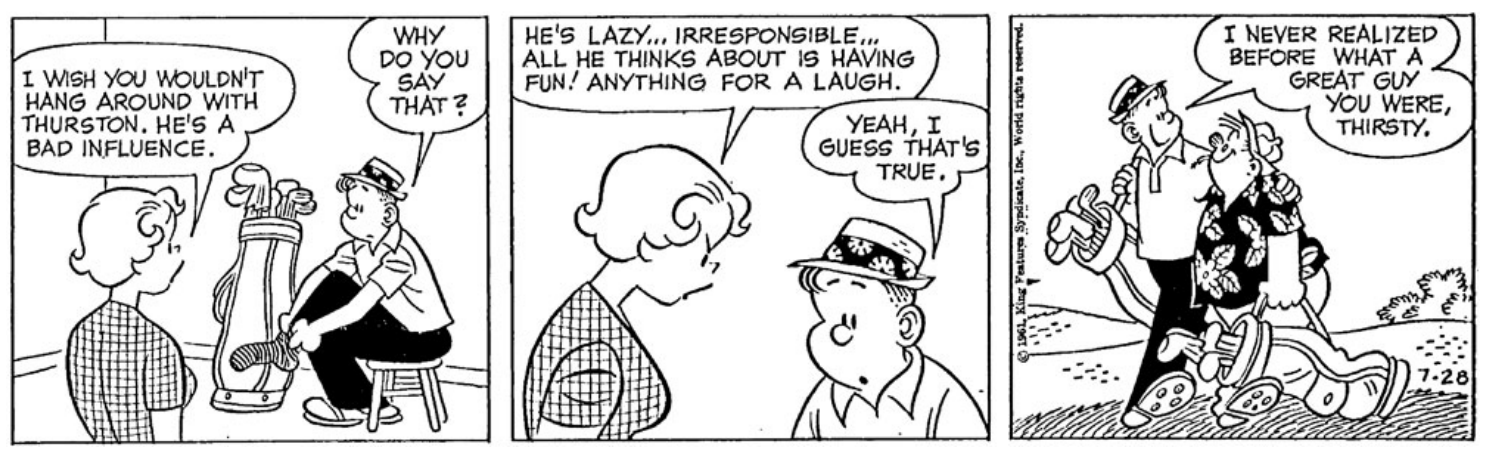

FIG. 9. Episodio del día 26 de junio de 1961.

\section{La gran familia americana}

Toda esa estructura, forjada diariamente, dio como resultado una de las familias más identificables del mundo del cómic. Logró imponerse como la número uno de su género entre los de su generación, por encima de The Flop Family (1943), de Dennis, the Menace (1951), de Family Circus (1960) o de The Born Loser (1965), en cuanto a popularidad y longevidad. Más de mil periódicos de difusión, con cerca de 80 millones de lectores en todo el mundo, pronto cumplirá los sesenta años de vida. Apelativos como amable, blanca e inofensiva han sido abundantes a la hora de analizar $\mathrm{Hi}$ and Lois, considerada la obra cumbre de la era Eisenhower. Y no hay que entender tales adjetivos como una crítica, ni mucho menos, pues ese era el objetivo de Walker y Browne cuando se pusieron manos a la obra. Su humor no hace sangre, no se nutre de

CuCo, Cuadernos de cómic número 1. Septiembre de 2013 
ridiculizar a terceros, es tierno, comprensivo, cercano, sutil. Pone el foco tanto en lo específicamente cotidiano como en las mayores generalidades, buscando siempre la complicidad del lector. Sin huir de los temas más polémicos: la guerra fría, el enfrentamiento diplomático con la URSS, el anticomunismo, la violencia doméstica, la guerra de sexos, la inflación, los debates políticos. Y lo ha hecho respetando el espíritu primigenio con el que fue concebida, una mezcla de costumbrismo, buenas intenciones, apego a la realidad, una fórmula bien resumida por Charles Saxon en la introducción del libro The Best of Hi and Lois (1986), coordinado por Brian Walker:

\begin{abstract}
No encontrarás crueldad en el mundo de los Flagston. Ni tampoco clichés en sus guiones. Cada episodio contiene buenos directos pero raramente puñetazos definitivos. Hi and Lois es acerca de gente real en situaciones reales lo cual explica cómo ha conseguido una audiencia tan numerosa y tan fiel. Sus seguidores no buscan brillantes golpes de humor, sino pasar un buen rato con una familia con la que sienten especial afinidad. Les gusta ser como ellos. ${ }^{8}$
\end{abstract}

Cuando se inició la tira dominical, el 14 de octubre de 1956, casi dos años después de su estreno, empezó a colaborar en los guiones un joven Jerry Dumas, que con el tiempo dibujaría, también para Walker, Sam's Strip (1961). Él fue el primero de toda una serie de asistentes: Bob Gustafson, a partir de 1962, el hijo mayor de Walker, Greg, a principios de los setenta, o el pequeño, Brian, ya bien entrados los ochenta. Gradualmente Mort Walker fue desentendiéndose, dejándolo todo en sus manos, lo cual supondría una paulatina merma de la calidad de la serie. Otro tanto sucedería con el apartado gráfico en el momento en que Dik Browne abandonaba los lápices en favor de su hijo Bob en 1981, por problemas de salud, ocho años antes de fallecer. El trazo finísimo y dulce de Browne se mostró algo fondón en su última etapa, casi en la misma mesura que su personaje, $\mathrm{Hi}$, descuidaba su forma física, cuando se ahogaba si salía a hacer jogging con Chip. Perdió el interés por el detalle, por los infinitos complementos que con anterioridad habían poblado sus viñetas, se despersonalizó y se dejó llevar por una línea más gruesa, en exceso ahorradora, en exceso sencilla. Una deriva a la que a contribuyó sobremanera sus obligaciones para con su segunda serie, Hägar the

\footnotetext{
${ }^{8}$ WALKER, B. Op. Cit., p. 9.
} 
Horrible, creada con éxito en 1973, por la sencilla razón que Browne no tenía la propiedad sobre Hi and Lois.
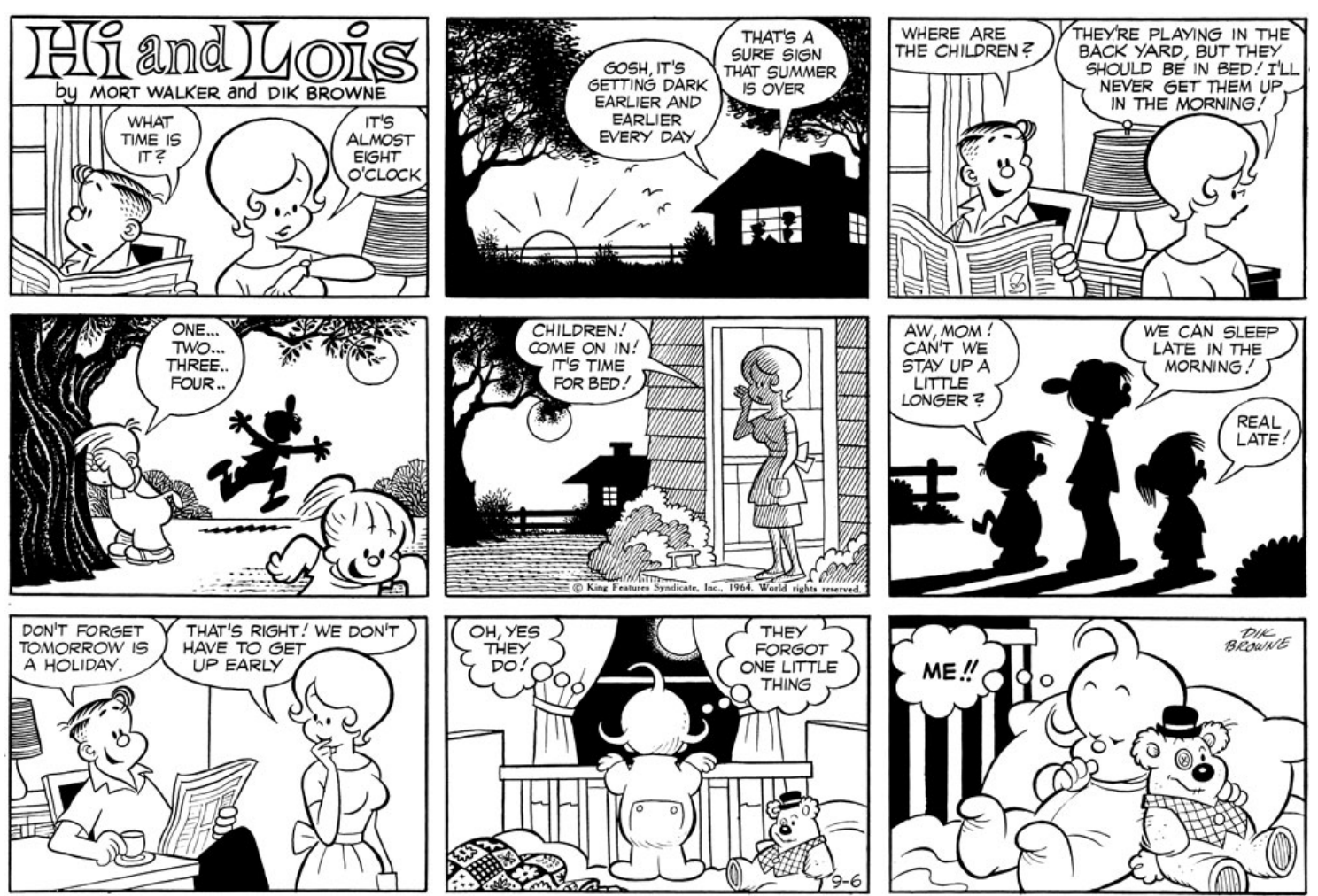

FIG. 10. Plancha dominical del 6 de septiembre de 1964.

CuCo, Cuadernos de cómic número 1. Septiembre de 2013 